\title{
A Top-Down Creation of a Cultural Cluster for Urban Regeneration: The Case of OCT Loft, Shenzhen
}

\author{
Jung Won Sonn*,\%,\#, Kelly Wanjing Chen**, He Wang ${ }^{+}$, and Xiao Liu ${ }^{++, \wedge}$ \\ *Bartlett School of Planning, University College London \\ ${ }^{\%}$ Institute of Management and Policy, Chinese Academy of Science \\ **Department of Geography, University of Wisconsin, Madison \\ ${ }^{+}$Department of Public Policy, City University of Hong Kong \\ ${ }^{++}$College of Management, Shenzhen University \\ ${ }^{\wedge}$ Corresponding author \\ \#During this research, Jung Won Sonn had financial support from the Ministry of Education of \\ the Republic of Korea and the National Research Foundation of Korea, grant code NRF- \\ 2015S1A3A2047036.
}

\begin{abstract}
Researchers of related topics agree that the large-scale top-down development of a creative cluster by a real estate developer may obstruct rather than facilitate creativity and creative entrepreneurialism. OCT Loft, a design industry park in Shenzhen, China, is being celebrated as an exception. Based on analyses of primary and secondary data, we find that the Loft's success can be attributed to two factors. First, the choice of design as the target industry was appropriate. Design is a fast-growing industry and thus needs space for expansion. Second, the developer chose tenants with good reputations in the industry rather than those offering the highest rent. Both these factors are difficult to implement. First, a growing industry is hard to find in a city where urban regeneration is needed. Second, the majority of developers cannot pass up maximising rent for a good reputation as OCT did. Indeed, OCT was able to pursue the Loft's creative success because giving a good impression to potential clients was expected to result in future opportunities that would raise profit further. In sum, a large-scale top-down development can facilitate creative entrepreneurialism but only when the developer is not hasty in demanding an immediate return on investment.
\end{abstract}

KEYWORDS: Shenzhen, China; cultural industry cluster; creative industry cluster; urban regeneration, Overseas Chinese Town (OCT); design industry.

\section{Introduction}

The predominant view in the literature on creative industry and creative clusters is that a large-scale top-down development by a real estate developer or the government to construct a creative cluster is likely to result in a strict environment in which creative thinking is discouraged. This view also asserts that a large input of capital is likely to result in gentrification, pricing out creative individuals and small firms and thereby killing the vibrancy of the area. From this perspective, the endogenous development of local cultural communities and bottom-up efforts to preserve such communities are effective at fostering creative development. 
Huaqiaocheng Chuangyi Wenhua Yuan (“华侨城创意文化园'), or OCT Loft, is regarded as an exception. OCT Loft, located in the northeast corner of Huaqiaocheng, Shenzhen, is a cultural and creative industry-led regeneration based in an abandoned industrial complex. Established in 2004, the South Park was first developed for design, photography, animation, and fine art. The North Park was finished in 2007, focusing on the creative design industry, including artistic trading and display platforms. Over the past decade, OCT Loft has become the largest design cluster in Shenzhen as well as one of the largest creative industry clusters in China. Its fusion of art and design products has also become a tourist hotspot. For us, the most interesting character of the Loft is that it was planned and managed in a top-down manner by the developer. In the planning stage, the developer offered few opportunities for citizens, small businesses, or workers to participate in the decision-making process. Further, the management of the Loft since its opening has continued in a similar manner.

This study addresses three related questions. First, is this design industry park an exception to the established findings? Second, if it is an exception, what enabled OCT Loft to accomplish what others could not? Third, can the same approach be applied to other projects?

We combined primary and secondary data to analyse this cluster. Primary data were collected by the authors through site visits, seven brief face-to-face interviews, 13 indepth face-to-face interviews, and five in-depth telephone interviews from February 2012 to July 2015. The in-depth interviewees included key informants such as high-ranking managers of real estate development companies, leaders of cultural communities in Shenzhen, shop owners in the Loft, a national brand fashion company manager, public sector urban planners and designers, OCT Loft Company employees, and employees of the architectural firm that designed the Loft. Secondary data were collected from various official and unofficial websites of selected cultural industry clusters, newspaper articles, and policy documents by local governments and the developer. The names of the interviewees that appear in this paper are pseudonyms.

The rest of the paper is structured as follows. The second section reviews studies of cultural industry clusters in China, especially the predominant critiques on the top-down management style. The third section examines the development trajectory of OCT, followed by a close evaluation of its success in the fourth section. The fifth section seeks to explain this exceptional successful case. Finally, we conclude with policy implications.

\section{Criticism of the top-down management style in the development of the cultural industry cluster in China and beyond}

Cultural industry clusters, creative cities, creative clusters, culture-led regeneration, and other related concepts have gained worldwide prevalence in research and policymaking on economic and urban development (Florida, 2002, 2005; Hall, 1998, 2000; Markusen, 2013; Scott, 1996, 1997). In the Chinese context, research on cultural industry clusters and culture-led urban regeneration is relatively new, but is expanding rapidly. Historical descriptions of notable cultural industry clusters such as Liulichang (Sun, 2010), Songzhuang (Liu, Han, and O'Connor, 2013; Sun, 2010), and 798 (Wang and Li, 2009; Sun, 2010; Liu, Han, and O'Connor, 2013) in Beijing, M50 (Zhong, 2010) in Shanghai, and White Horse Lake in Hangzhou (Wen, 2012) have been documented. 
Culture-led regeneration sites such as Nanluoguxiang, Beijing (Shin, 2010) and Red Town, Shanghai (Wang and Li, 2009; Zhong, 2010) have also been reported. Even Dafen Oil Painting Village, the world's largest concentration of art replica producers, has attracted academic attention ( $\mathrm{Li}$, Cheng, and Wang, 2014). There has also been an ambitious attempt to chart the landscape of cultural districts across China (Webster, Muller, and Cai, 2011: 365-366). National and local governmental policies as a context for cluster development have also been studied. Kean (2009a, 2009b) focuses on the national framework, while White and $\mathrm{Xu}$ (2012) describe how the national framework interacts with Shanghai's local history and political elite's efforts toward transforming the city. The locational analysis of cultural industry clusters has also been published. Liu, Han, and O'Connor (2013) find some evidence that cultural industry clusters in Beijing are often situated on the city's fringe where cheaper industrial buildings exist because of the relocation of firms. On the contrary, clusters in Shanghai are located in historical districts according to He and Gebhardt (2013).

The criticism of cultural industry clusters in China is similar to that in Western Europe and North America. To improve the aesthetic appeal to a 'creative class' (O'Connor and $\mathrm{Gu}, 2012$ : 1), so-called cultural industry clusters overcommercialise culture and lose the authenticity that distinguishes cultural products from other products (Keane, 2009a, 2011; White and Xu, 2012). In the process, 'history and memory are romanticized and sanitized, and the concept of art and artists is redefined' (Wang, 2009: 329). This tendency often results in increasing real estate prices, which drives out artists (Wang and Li, 2009) and undermines the vibrancy of creative clusters. According to Wang (2009: 329), 'the irony is that while the project was initially based on artists' space consumption, these artists themselves - particularly the struggling ones - were not truly welcome in the new creative community'. In the end, little of the cultural industry cluster development contributes to nurturing a creative workforce or creative entrepreneurism (Zheng, 2011). In this context, He and Gebhardt (2013) criticise clusters in Shanghai for being planned and developed by the government and developers more for tourists than for creative industries. Ren and Sun (2011) attribute these problems to the fact that the clusters were developed top-down by real estate developers and the local government rather than bottom-up by artists and residents.

The survival of creativity in a government-controlled environment is considered to be near impossible. For example, Ren and Sun (2012: 518) ask whether the government's control over clusters will 'suffocate urban creativity' or lead to the migration of creativity. This view is in line with the observations of many researchers. Webster, Muller, and Cai (2011) claim that 'the most successful bottom-up cultural industry clusters are driven initially by the artists ...not by intermediate property developers' (365-366). This is rather surprising to us because even 798, which was considered to have formed spontaneously, has actually received increasing support from central and local governments in recent years (Zhang, forthcoming).

Unfortunately, the naïve celebration of spontaneity and neglect of the effect of topdown management measures are both common in writings on various kinds of creativity. Howkins (2010), a renowned consultant in cultural industries and policies, argues that although everyone has creative potential, such potential can only be realised when people are given freedom. Even in high-tech industries, economic geographers have argued that the success of Silicon Valley is partly a result of northern California's hippie culture in 
which all individuals are equal and are allowed to express their ideas without being restricted by the social hierarchy (Saxenian, 1994). This view of individual creativity seems to be an assumption in endogenous regional growth concepts such as the regional innovation system (Braczyk, Cooke, and Heidenreich, 1998) and institutional thickness (Amin and Thrift, 1994), among others, which reject political intervention by the national government.

Although less known outside China, OCT Loft, a design industry park and cultural quarter, is celebrated as an exception to the predominant view in the literature. Both academics (O'Connor and Liu, 2014) and journalists (O'Donnell, 2012) depict this major project as an emerging national centre of the design industry and an attractive cultural venue. Its success has been expressed not only by the job opportunities and GDP growth it has created - in 2015, OCT Loft generated an output of 11.2 billion CNY and 2,000 employment opportunities - but also by its reputation within the design industry, the cultural products it has generated, and the associated goodwill. On 19 November 2008, Shenzhen was invited by UNESCO to join the creative network and was awarded a 'City of Design' recognition. Several of our interviewees claimed that OCT Loft contributed to such international recognition. In the following sections, we examine how and why the Loft is different from other large-scale top-down developments.

$<$ Figure 1. Location of OCT Loft in Shenzhen>

\section{Is OCT Loft different from other major culture-themed developments? 3.1 OCT Loft and its developer}

In the context of OCT Loft, Shenzhen was the first of China's five special economic zones and the most successful one. The Shenzhen Special Economic Zone was opened in 1979 by Deng Xiaoping, who realised that the city's proximity to Hong Kong made it a good site to experiment with an open economy. Since then, the city has developed rapidly. In 1979, Shenzhen was a fishing village inhabited by several thousand residents. Currently, it is a major city with 10 million residents, about six million of whom are migrant workers housed in factory dormitories.

In the beginning, the city grew based on foreign direct investment that sought lowcost assembly at a large scale. The city's economy gradually upgraded and now it hosts some of the most innovative companies in China. By some measurements, Shenzhen is the most innovative city in China (Sonn, 2017). In 2015, the city's GDP per capita was US\$21,643 (Statistical Bureau of Shenzhen, 2015), one of the highest among all major cities in China. This economic growth is reflected by fast development in a built environment, which is succinctly summarised by what people said about Shenzhen in the 1990s: 'one high-rise a day and one boulevard every three days'. Even by Chinese standards, where large-scale developments are rapidly completed (Li, 2015), Shenzhen's physical development has been unusual. While the decentralisation of state finance has made all cities compete for growth, Shenzhen is one of the most aggressive (Davis, 2016; Ren, 2015; Shi and Chen, 2016).

OCT Loft is situated within the northern section of the East Industrial Zone of OCT Shenzhen. The Loft is divided into the South and North Parks that cover approximately $0.15 \mathrm{~km}^{2}$ (Xie, 2012). The South Park covers $55,465 \mathrm{~m}^{2}$. Its floor area is $59,000 \mathrm{~m}^{2}$. The 
North Park covers 95,571 $\mathrm{m}^{2}$ and has a floor area of 150,000 $\mathrm{m}^{2}$ (Shi, Zhu, and Qing, 2012).

According to the official statistics of OCT Loft (2015), there are seven exhibition halls, 129 design-related firms, and 27 non-design businesses. The design-related firms include architectural design studios, furniture design studios, cartoon firms, entertainment businesses, industrial design studios, fine art studios, art agencies, bookstores, galleries, animation studios, fashion houses, food companies, magazine publishers, and other creative agencies. However, many of our interviewees indicated the existence of even more entities in the quarter because the directory is not updated frequently and smaller sublets of space are not included. Indeed, Zhou and Yu's (2015) estimate might be more credible than the official statistics. They claim that of the 221 businesses, 151 are in various creative industry sectors.

The area attracts tourists as well as design professionals because it offers hotels, restaurants, and bars and it frequently hosts high-profile art- and design-related activities such as exhibitions, lectures, seminars, and fairs. Some of the most high-profile activities held in OCT Loft include the Shenzhen/Hong Kong Bi-City Biennales of Urbanism/Architecture, the International Jazz Festival, the T-Street Creative Fair, and the Shenzhen Biennales of Independent Motion Pictures, each known to host some of the best achievements in its field in Mainland China.

The Huaqiaocheng Jituan Gongsi (华侨城集团公司), or Overseas Chinese Town (OCT) Group, used its various arms; however, OCT Real Estate, the real estate arm of OCT Group, was in charge. The Xiangning Art Museum and its subsidiary, the OCT Contemporary Art Terminal (OCAT), also participated in the planning and investment process (interview with Mr. Wang, a mid-level manager at the OCT Loft Company, on 8 February 2013). The Loft Company, set up to manage the Loft, is a subsidiary of OCT Real Estate.

OCT Group is a Shenzhen-based large-scale state-owned holding company that owns tourism, real estate, and electronics manufacturing businesses. Tourism is considered to be its main business. OCT is arguably the largest brand name in the Chinese tourism industry. It owns popular theme parks such as Happy Valley and Splendid China in major cities in China. It also owns several hotel chains. Simultaneously, OCT is also one of the largest real estate developers in China. The OCT Group is a state-owned 'key enterprise', a status given to some of the largest and most important state-owned firms in China (OCT Group, 2014). This status within the government hierarchy is actually higher than the status of the City of Shenzhen, which is a sub-provincial-level city. This implies that the company wields strong bargaining power over the local government when making planning decisions. Within the industry and market, OCT is considered to be a high-end property developer (interview with a realtor conducted on 12 February 2012).

\subsection{Development Process}

Before its development, the site was an industrial park owned by OCT, or Huaqiao Cheng. During the 1990s, the Eastern Industrial Zone housed nearly 60 industrial enterprises, including electronics firms such as Konka Group and a large number of lightindustry enterprises (Xie, 2012). These factories gradually left the site as wage levels 
increased and the city's economic structure changed. Simultaneously, as the city grew, the site became more attractive to other potential land uses.

Factory conversions began in 2004 in the area now known as the South Park. The quarter began to host major cultural institutions such as the Contemporary Art Centre (a non-profit), a subsidiary institution of the National Art Museum, which is owned and managed by the OCT Group. The Loft's debut occurred in December 2005, when it hosted the first Shenzhen/Hong Kong Bi-City Biennale of Urbanism/Architecture.

The total cost of the initial construction of OCT Loft approached 30 million yuan. The construction costs for the Contemporary Art Centre alone amounted to 20 million yuan (Jin, 2013). This was an unusually high level of investment, considering that the prospect for profits was unclear. Urbanus Architecture \& Design, a prestigious Hong Kong-based architectural firm, was hired to design the Loft. Once design and planning began, the OCT Group began to search for potential tenants.

The OCT Group found inspiration from external sources. Experts worldwide were asked to sit on its advisory board. That list of advisors included Deyan Sudjic, the curator of Design Museum London, and Taku Satoh, the director of 21_21 Design Sight, as well as other well-known names within China. Yifei Chen, one of China's most renowned contemporary artists, was invited and listened to. He warned that if individual designers were to occupy the Loft, it would end up becoming like 798. He suggested that OCT should bring in established firms and organisations. That suggestion was well integrated into the development plan of OCT Loft (OCT Loft Company, 2014).

Mr. Sun, a mid-level manager at OCT Real Estate, stated that external influences have affected the Loft's theme (Interview on 8 February 2013). In or around 2003, the concept of 'the Loft' had spread widely because of the extensive media coverage of Beijing 798. Research on 798 led OCT researchers to search for and gain a better understanding of similar cases globally. A team of researchers helped OCT management conclude that Yaletown, Vancouver offered the most transferrable model. They thought they could do better than 798, Xintiandi, or M50 and become the best in China by learning from overseas cases rather than from Chinese cases. Design was chosen as the theme of the development because researchers and the OCT Group's decision-makers believed design was the only theme in which Shenzhen had a competitive advantage. We were repeatedly told by our interviewees that the choice of design was obvious. Shenzhen is a new city inhabited by a young, hard-working population. It does not have the institutional and cultural foundation for classical or contemporary fine arts that Beijing has (interview with Ms. Jia, a writer for OCT Magazine, the company's internal magazine on 8 February 2013).

The first tenant, Kenneth Ko, moved into the Loft in 2003. Kenneth Ko is a successful designer/celebrity. When the Loft was officially inaugurated in January 2007, it already contained more than 20 institutions (NEWS GD, 2007). At that time, in addition to Kenneth Ko's workshop, the list of institutions included the offices of a celebrity designer from Hong Kong, Liang Jinghua, Urbanus Architecture \& Design, Hongbo Information Company's animation design base, and the OCT International Media and Entertainment Company.

<Figure 2 OCT Loft master plan (Source: Liu, Meng, and Wang, 2013)> 
In the same year as OCT Loft launched with the near-completed South Park (Figure 2), the North Park's development began. While the South Park mixes cultural production and consumption with amenities, the North Park focuses on uses directly related to design industries such as workshops and exhibition spaces. The North Park officially opened on 14 May 2011. According to Zhou and Lei's (2015) survey, the respective shares of creative industry firms and retail shops are $74 \%$ and $15 \%$ of the 165 establishments in the North Park, while they are $52 \%$ and $45 \%$ of the 56 establishments in the South.

\author{
$<$ Figure 3. South Park> \\ $<$ Figure 4. North Park>
}

Throughout this process, the Shenzhen government provided both formal and informal support to the Loft. Formally, the city offered tax cuts to design firms that lease space in the Loft. Informally, the city instituted informal zoning changes. To ease the application and bidding procedure, the local government allowed OCT to use lands for different uses, even though the lands are located within the industrial zone. Cultural industrial use is acceptable in the industrial zone; however, there are numerous shops and stores in the Loft. As long as the shops nominally comply with the document's zoning regulations, the local government informally overlook its actual use. (Interview conducted with Dr. Pu, an elite planning consultant, on 8 May 2012).

\title{
4. Evaluating OCT Loft
}

The success of OCT Loft can be inferred from its growing annual output. In 2012, only a year after the grand opening of the entire OCT Loft (including both the South and the North Parks), the annual output of its tenant firms reached US $\$ 1.17$ billion. That figure rose to US $\$ 1.36$ billion in 2013 and to over US $\$ 1.5$ billion in 2014. Its estimated total employment of over 2,000 individuals makes it comparable to China's most famous cultural and creative industrial clusters such as 798 (Zhang, 2014).

Most interviewed employees and tenant firm owners in the Loft claimed that it has cultivated a culture-rich and artistic atmosphere through its overall planning and operation, which significantly benefits both the reputation of the firms and their everyday practice. It was also acknowledged by the interviewees that the designers of the Loft create their own unique designs rather than copying existing ones as most design firms in Shenzhen do. As Shi, Zhu, and Wan (2012) recognise, the presence of leading Chinese industrial design firms such as LKK Design, Thray, and Ciga Design is a good indication that the Loft has become one of a small number of places where original designs are created.

According to Kenneth Ko, who has advised developers of cultural and creative clusters in Mainland China (e.g. 798 in Beijing and Kuanzhai Alley in Chengdu), 'OCT Loft is particularly good in that it has successfully developed and maintains an atmosphere that a cultural and creative cluster should have'. Formal and informal interactions among firms are also common. Mr. Gao, the owner of a brand design studio, confirmed that he often cooperates with design studios that have complementary specialties (interview conducted on 7 July 2015). 
This cultural quarter also attracts business visitors from within and outside the city and region. During our random interviews with customers in a Starbucks Coffee Shop in the South Park, we met two professionals who work for a mid-size property developer at Changsha. Their company was considering a contract with an interior design company in the Loft for its next apartment project and they were contemplating the purchase of furniture they could use in their show apartment. They stated that Shenzhen's design firms and those located in the Loft in particular are regarded as the best in the country. However, the two disagreed on one point. When one of them said, 'We came here instead of Shanghai and Beijing because firms in those cities set the price too high', the other countered, 'I think Shenzhen is the best in interior design and furniture design not only in terms of low price but also for its high quality'.

The Loft is regarded as a 'chic place' in the city, and it attracts both local consumers and tourists. Given that most shops in the Loft are run by designers, they have a sophisticated décor and unique features. For example, chefs and kitchen staff play jazz music in a noodle shop, small exhibitions take place in craftwork shops, and decorations collected from all over the world are displayed in a hair salon. In Idutang, a bar in the Loft, Chinese rockers, Mongolian folk singers, German guitarists, and American jazz singers perform every night. There are also several high-end and mid-range Chinese, fusion, and Western restaurants. All of these cultural elements blend into the other businesses in the Loft, and lay a foundation for its 'coolness' factor. Leaders of the local cultural scenes and affluent expats are attracted to the Loft's atmosphere. Young local people hang out there, too. In 2015, because of the popularity of the T-Street Creative Fair among tourists, the Loft management centre held the event twice a month instead of once a month to satisfy the demand of visitors.

The success of OCT has created various effects that are not easily quantified. Many entrepreneurs think that being a tenant in the Loft is beneficial. According to Mr. Gao in the interview cited above, a client 'has a lot more respect for and interest in us because we are at OCT'. For Omnialuo, moving to the Loft was a signal that the company is different from the rest of the city's clothing industry and that it wants to be known for its original designs (Mr. Cu, an executive of Omnialuo, interview on 13 January 2012).

Many firms still try to rent space in the Loft, even with the rent being so costly, but fail in the application process for various reasons.

Generally, the successful development of a cultural quarter is likely to cause three problems: changes of space use, displacement of residents, and affordability (Evans, 2005, 2009; Rantisi, 2004; Zukin, 1982). Although the change of space use did happen in the Loft, the developer found a reasonable solution. The success of the initial development, currently known as the South Park, led to the commercialisation of the space. Restaurants, bars, and coffee shops replaced design studios. In response, OCT constructed a new space specifically for design studios in the North Park. The second potential problem, the displacement of residents, was not too large a concern for the Loft development, either. The area's original tenants were factory workers who had to move when their jobs were relocated to more peripheral areas of the city. Indeed, many old factory buildings were already abandoned by the time the initial conversion started. Therefore, unlike many other successful redevelopment cases, only minimal criticism related to the displacement of the original residents was expressed. 
Unlike the first and second potential problems, the third problem materialised. With the success of the Loft, the OCT Loft Company increased rents to a level unaffordable for small design firms and start-ups. One designer/entrepreneur, Mr. Chang, complained that 'Famous firms get benefits but (the) small, less famous end up paying the full fee'. Yet, he admitted that OCT rents remain cheaper than rents in the CBD area (interview conducted on 12 February 2012). According to Ms. Jia, a writer for OCT Magazine, based on the OCT Loft's considerable popularity, the OCT Loft Company changed tenancy contracts from initial five-year leases to three-year leases. Ultimately, they only issued one-year leases. She also attributed recent rent increases at wider OCT development to the Loft's success. Lily's view was supported by a realtor who claimed that the area immediately adjacent to the Loft experienced about a $100 \%$ increase in rents over the past 10 years. Although inevitably complaining about the rising rent, firms still show a strong preference for sticking around rather than looking for a cheaper location.

Given all the evidence, it seems reasonable to conclude that OCT Loft accomplished a certain level of success according to various standards. In the next section, we search for the reasons behind its success.

\section{Explaining its Success}

To explain the reasons for the success of OFT Loft, the advantage of its host city, Shenzhen, cannot be overlooked. As noted in Section 3.1, Shenzhen is an advantageous location for a cultural industry cluster. Even in Shenzhen, however, not all projects are successful. For example, the Annual Shenzhen International Cultural Industry Fair, part of the local government's ambitious plan to be the centre of the cultural industry in China and beyond, has struggled to internationalise (Qianhai Media, 2016). The success of OCT Loft, aside from its favourable Shenzhen location, should thus be understood. Our analysis shows two prominent factors.

\subsection{The right choice of target industry}

The first factor is that the choice of design as the target industry was appropriate, as touched upon in Section 3. The design industry's prominence is related to the city's rapid growth. A huge number of houses for families had to be built when the population increased from several thousand to 10 million over the course of three decades, even though a large percentage of that population increase consisted of migrant workers housed in dormitories. The production of housing, in turn, increased demand for various design services such as architectural and interior design, furniture, and decorative art design. At the same time, an increasing number of start-ups as well as some of the largest IT companies in Shenzhen demanded advertising, web design, and other design-related services (interview conducted with Mr. Chang, designer/entrepreneur, on 12 February 2012).

On the supply side, the city's status as a free economic zone and its proximity to Hong Kong strongly influenced its ability to attract talent and learn from advanced, imported practices. Since the late 1980s, Shenzhen has attracted many young artists and designers. These individuals have created small firms to sell their designs to Shenzhen's large manufacturers and property developers. This led Shenzhen to be one of the few cities in Mainland China where young designers can find opportunities to build their careers (interview with Mr. Chang, designer/entrepreneur, on 12 February 2012). Mr. 
Chang also praised Shenzhen as one of the few places in China where designers could closely observe the latest international trends in design, branding, packaging, and advertising. Shenzhen's proximity to Hong Kong offers inhabitants access to all major global brands. Consequently, design professionals in Shenzhen are proud of themselves. Furthermore, in our interviews in 2012, various design professionals claimed that 'the designers in Shenzhen are at the top level in China'.

Shenzhen does not host a prestigious art school. Therefore, the city is unable to educate its own creative workforce. In addition, Shenzhen does not host a local branch of the Chinese Artists Association, which has branches in most major cities in China. While this may have disadvantages in terms of the supply of young talents, the absence of authoritative figures such as art professors and older artists has allowed young designers to develop a higher sensitivity to market demand (interview with Mr. Chang, designer/entrepreneur, on 12 February 2012).

In 2007, around the time when the South Park was completed, the annual output of Shenzhen's cultural and creative industry reached US\$7.7 billion, accounting for $6.8 \%$ of the city's GDP for that year. Over 6,000 design companies, collectively employing more than 60,000 designers, clustered in the city at that time. The Shenzhen government tried to gain the support of the cultural and creative industries in 2004. The strength of the design industry in Shenzhen is now widely acknowledged. (Yang and Huang, 2010).

A cluster development is more likely to succeed if the target industry is growing quickly. As Sonn and Liu (2014) argue, the best target industry is one growing in volume but that does not have a strong spatial core. Although design did have a spatial core in downtown Shenzhen, the industry needed a new core for two reasons. First, the expanding industry required more physical space. Second, aesthetic standards rose along with the growth of Shenzhen's economy. Firms that successfully adjusted, or that wanted to adjust, to this higher standard wanted to detach themselves from the existing cluster. As exemplified by Omnialuo, this new generation of creative firms preferred a new location with a better physical environment. The choice of design as the target industry was the right one.

\subsection{Tenant selection and monitoring}

In our fieldwork, many of our interviewees praised OCT Real Estate for maintaining rigour in tenant selection. In the previous section, we briefly noted that during the early phases of development, OCT carefully handpicked its first group of tenants. Rather than advertising to the public, the management targeted a small number of designers considered to be prestigious by both the industry and the public.

After choosing design as the target industry, the OCT Group carefully chose its tenants. It selected tenants that would not compromise the quarter's theme. According to Mr. Wang, a mid-level manager at the OCT Loft Company, the first tenant group was extremely important because a careful selection of high-profile designers would signal the OCT Group's commitment to the Loft to citizens, the media, and the country's powerful politicians. It would also demonstrate the type of cultural quarter the OCT Group hoped to build (interview on 8 February 2013).

Ms. Jia (a writer for OCT Magazine), Mr. Chang (designer/entrepreneur), and several other interviewees stated that the OCT Group offered selected tenants rental rates that were much lower than market rates. This is confirmed by information we gathered 
from the firm side. The senior manager of the Alliance Art Group, arguably one of the most influential firms in the art and entertainment arena as well as among the first to move into the northern part of the Loft, said that the Group was offered a rental rate in the Loft that was more than $10 \%$ lower than the market rate. Most interviewees, however, refused to reveal the details of their rental policy and admitted that rent varies among tenants. The first few high-profile tenants, especially OCAT, Kenneth Ko, Liang Jinghua Design Studio, Xiangning Art Museum, and Omnialuo, were instrumental in establishing the prestige of the Loft.

Once the Loft was relatively well established, the management allowed all interested parties to apply for space. However, the selection process was not completely marketised. For one, OCT continued hunting for preferred high-profile art- and design-related firms. The case of the Alliance Art Group in 2010, an influential firm in the art and entertainment arena, illustrates this selection process. According to its senior manager, several cultural and creative parks in Shenzhen indicated their interest when the firm was looking for a new location to relocate its expanding workforce. However, the Loft Management Company and Nanshan District government offered favourable conditions to this company, with the understanding that its inclusion would add to the Loft's prestige. Both OCT and the Nanshan District government offered an approximately $8 \%$ reduction in rent, which the Alliance Art Group found preferable.

In addition to offering incentives to preferred firms, many of our interviewees who were tenants at the Loft indicated that the Loft Company had strict criteria for selecting tenants from the large numbers of applications it received. The owner of a design bookstore indicated how competitive the process was. According to him, many bookstore owners wanted space in the Loft, but he eventually was chosen because 'they learned that [my] bookstore had a unique theme that fit in well with the overall concept of the Loft'.

During selection, the Loft Company places more weight on the visions and business plans of applicants than on their predicted size and profitability. Applicants are required to present their vision and plan through a detailed slideshow to Loft Company executives. Even invited firms such as the Alliance Art Group are required to go through the same process. Many potentially influential applicants have failed such a process. For instance, a company whose name was not revealed to us applied for $6,000 \mathrm{~m}^{2}$ of office space for over 100 workers. The application was rejected because the decision-makers at OCT Loft felt that a large company's occupancy of such a space would reduce the potential for diversity within the Loft (interview with Lily, an urban designer, on 14 February 2012).

After gaining tenancy, the tenants are still under the Loft's strict supervision. The Loft monitors tenant firms and evaluates their progress against their submitted plans. Those that have developed products or services that diverge from the Loft's view, or those that are not performing well, are sanctioned through rent policies. The Loft Company negotiates rent with each individual firm and offers a favourable price to those worth supporting, while raising the price to those they want to remove, according to the manager of the Alliance Art Group and several other firm owners in the Loft.

It is through such a combination of strategic invitation, strict selection, and continued monitoring that the Loft is able to maintain a collection of high-quality tenant firms. These restrictive management strategies, however, go against the common view of the conditions for creativity. As we saw in Section 2, freedom is commonly thought of as 
an important condition for creativity. However, those involved in OCT Loft management believe otherwise.

An executive from the OCT Group argued such a tight management style is essential to the Loft's success. She does not believe that creative people can self-govern. She argued that 'those creative types are not good at managing things' and that is why OCT 'provides a clear guideline (as to) what designers can do and what they can't do' (interview on 12 May 2012). She also claimed that creative enterprises tend to lack management skills and long-term strategies. The creative community's much-celebrated creativity, diversity, and spontaneity can be accompanied by short-sightedness, financial instability, and a lack of continuity. Ms. Jia, a writer for OCT Magazine, agreed when she said, 'If the quarter is left to manage itself, it will destroy itself.' Mr. Sun, a mid-level manager at OCT Real Estate, went a step further. He argued that it is better to set clear boundaries and leave little room for negotiation in terms of the business plan and vision of the Loft because 'designers have strong egos. Everyone thinks he is the best. They need management by someone who can kick them out'. (Interview on 8 February 2013)

However, the executive did admit that OCT's tight management style might negatively affect community-mindedness among the designers who rent space. She argued that this issue is partially addressed by the participation mechanism. Yet, to the authors of this paper, the activities described by the editor and other interviewees sounded more like unpaid labour than participation. For example, Omnialuo has to organise receptions when the OCT Group has high-profile visitors such as high-ranking officials from the central government, even if the visit is not related to OCT Loft. Smaller tenants are also required to 'participate'. Mr. Chang, a designer/entrepreneur, stated that all his friends who rent a small space in the Loft 'help in one way or another'. He has personally helped the company recruit designers, engaged in exhibition planning, and participated in designing the Loft magazine, among other tasks, although he has not yet relocated his office to the Loft (interview on 12 February 2012). A senior manager from the Alliance Art Group also confirmed that OCT provides bands and singers for activities taking place at the Loft, such as the opening of exhibitions and creative fairs. OCT may or may not offer financial compensation for the tenants' contributions. It can avoid paying compensation because the tenancy itself is regarded as a reward. Maintaining a good relationship with OCT management can thus be helpful when a tenant renews the rental contract. This type of tight management style is possible because OCT can invest large sums of money yearly in research and daily operations.

It should be noted here that these management strategies are not based on revolutionary new ideas. Indeed, such strategies are similar to those suggested by practitioners and academics for business incubators, high-tech clusters, and cultural industry clusters. The real question is why these strategies, which could not be implemented in most top-down developments, could be implemented at OCT Loft.

The main reason is that the Loft did not intend to make an immediate profit. According to Mr. Wang (interview on 8 August 2012), a mid-level manager at OCT, the developers were conscious of the danger that profit-seeking can bring. He said 798 in Beijing became a theme park-like place because the high rents there drove out artists. According to him, OCT could increase its profits by either selling the South Park or duplicating the South Park in the North Park, but it chose not to. The flea markets and 
jazz festivals cost money rather than earn it, but OCT still does these events because they attract creative professionals and add flavour to the Loft.

The OCT Loft Company in charge of managing the Loft is a subsidiary of OCT Real Estate. The company earns 60 million RMB rental income from the Loft. The other part of the income is the subsidy from OCT Real Estate. However, OCT Real Estate does not consider the Loft to be a charity mission because the value of the Loft clearly exceeds its income. According to Ms. Jia (a writer for OCT Magazine), the Loft is the showpiece of the OCT Group. It is used to demonstrate the group's sophistication. This further adds value to the prestige of OCT's brand name, thereby making OCT's projects such as residential development more profitable. It is also important when the company persuades political leaders in the national and local governments about opportunities for regenerations in other major cities (interview on 8 February 2013). In transplanting the Shenzhen OCT model into other major cities in China, including Shanghai, Beijing, and Chengdu, OCT Loft is frequently shown as an example of successful cultural-led urban regeneration (OCT Magazine, 2010).

\section{Academic and policy implications}

The Loft is a successful case of a large-scale cultural industry cluster development project in the sense that its creative workers and entrepreneurs are satisfied with the environment, the location is gaining prestige in the industry, and business visitors and tourists are attracted to it. The displacement of residents and gentrification, the most common negative outcomes of this type of regeneration project, are less severe than in other cases because the majority of the original residents were dormitory residents who worked in OCT factories and were willing to follow the relocation of factories.

The main reasons for the Loft's success are 1) its choice of industry and 2) its strict administrative controls in tenant selection and monitoring. While these sound like sufficiently simple ideas, neither is easy to implement. The Loft's choice of design as the target industry was possible because the design industry was growing fast and needed more and better space. Urban regeneration projects are more likely to be implemented in cities in which industries are declining rather than growing. As such, selecting a growing industry is often difficult. Most major regeneration projects are designed to host cultural industries, financial industries, high-technology industries, or prestigious retail. Yet, the total volume of those industries is limited in the national and global economy, meaning that not all such regeneration projects can host them.

Even after the right industry was chosen, had the developer wanted the immediate maximisation of profit, the Loft would not have been hosting all the prestigious firms it does presently. The fate of the project was heavily dependent upon the fact that OCT Real Estate did not aim for immediate profit. The purpose of the project was to show the ability of this ambitious developer as a means to win contracts for similar projects outside Shenzhen. The developer continues to strictly choose creative firms that are respected in the industry instead of those with higher rent bids. This reduces rental income, which a profit-maximising developer may not prefer.

As such, the Loft's success cannot be randomly transplanted in other cities. The key factor is to do it in a city that has similar conditions. The two conditions stated above seem rare because most culture-led regeneration has been attempted in deindustrialised cities in advanced economies where economic dynamism is long gone. In China, cities 
with the highest income levels are experiencing deindustrialisation without losing their wealth. It is more of an upgrade to their economic base rather than deindustrialisation in its traditional sense. In such cities, a cultural industry might still prosper and thus need more space to expand. Furthermore, in China and other high-growth economies, sacrificing short-term profit for a larger market share in the future is a common strategy, which is related to the country's risk-taking culture (Hsee and Weber, 1999). As such, it might be possible to find a developer such as OCT that is willing to pay a high cost to build a reputation that will lead to higher profits in the long run.

From a theoretical perspective, the findings of this study offer a criticism of the mainstream opposition to the top-down development of cultural clusters. At different scales, top-down management has proven to be effective when certain conditions are met. For example, as many social scientists agree, the state management played an important role in the economic success of East Asia (Amsden, 1989; Chang, 1994; Duckett, 2001; Johnson, 1982; Kim and Choi, 2015; Oi, 1992; 1995; Saich, 2010; Sonn, 2007; Sonn and Gimm, 2013; Sonn and Lee, 2015; Wade, 1990; Woo-Cumings, 1999; Walder, 1995; Wu, 2003). Such a process was hardly bottom-up. The authoritarian government decided which industry to support and how, with input from the top of business communities while disregarding demand from the bottom. Whether such a practice should be praised from political and ethical perspectives is also important question, but these successes do show that top-down management can be effective in some cases. The bottom-up strategy is not the only way for innovation to transpire at the firm level either. It has been the largest companies' R\&D labs that have produced the majority of innovations (Sonn and Storper, 2008), at least after the 1920s when R\&D became a part of normal business in large manufacturing companies (Rosenberg, 1983). Similarly, some of the world's greatest innovations occurred within the R\&D labs of multinational firms in Japan and South Korea (e.g. Sony, Toshiba, and Samsung), where the hierarchical culture is even more dominant than that in their Western counterparts.

If top-down management can drive innovation at the national or firm level, we cannot preclude the possibility of its effectiveness at the cluster level. The conventional answer would be that culture involves individual creativity, which flourishes only when individuals are given freedom to pursue what they want. However, psychologists of creativity generally agree that creativity is not an outcome of unrestricted freedom. Rather, an effort to work within restrictions or to overcome them is a more likely source of creation. Therefore, restrictions are not a barrier but rather a necessary condition for creativity (Sternberg, 1988). Resonating with this theoretical reasoning, OCT Loft punctures the myth in urban research about cultural industry clusters.

Although this study assesses top-down management by a real estate developer, topdown management by the state is also in the background. The development of the Loft was within the context of the promotion of creativity and cultural industries at the central government level, as manifested in the 10th Five-Year Plan (2001-2006) and the Ministry of Culture's Cultural Industries Revitalisation Plan in 2009 (Wen, 2012). The discourse of 'soft power' also sets the context for developments such as the Loft (Leonard, 2008). Being a state-owned company, the OCT Group is likely to want to comply with this trend at the national level. At the local level, in compliance with the central government's emphasis on creative industries, Shenzhen had been promoting itself as 'city of design', as mentioned earlier. Given the rising labour cost in the coastal 
areas of China, Shenzhen had to diversify its economy to various non-manufacturing sectors including cultural industries (O'Dennell et al., 2017). In that sense, the local government has been willing to support projects such as the Loft. This political context, to which the OCT Group probably gave serious thought, is an interesting topic for further research on the Loft.

\section{References}

Amin, A., Thrift, N., (Eds.), 1994. Globalization, Institutions and Regional Development in Europe. Oxford University Press, Oxford.

Amsden, A. H., 1989. Asia's Next Giant: South Korea and Late Industrialization. Oxford University Press, Oxford.

Braczyk, H., Cooke, P., Heidenreich, M., (Eds.), 1998. Regional Innovation Systems: The Role of Governances in a Globalized World. UCL Press, London.

Chang, H.J., 1994. Political Economy of Industrial Policy. Macmillan, London.

Davis, D., 2016. Reflections on the relations between development and urbanization: past trajectories and future challenges. Int. J. of Urban Sci. 20: 1-14.

Duckett, J., 1998. The Entrepreneurial State in China: Real Estate and Commerce Departments in Reform Era Tianjin. Routledge, London.

Evans, G., 2005. Measure for measure: Evaluating the evidence of culture's contribution to regeneration. Urban Stud. 42: 959-983.

Evans, G., 2009. Creative cities, creative spaces and urban policy. Urban Stud. 46: 10031040.

Florida, R., 2002. The Rise of the Creative Class. Basic Books, New York.

Florida, R., 2005. Cities and the Creative Class. Routledge, New York.

Hall, P., 1998. Cities in Civilization. Pantheon, New York.

Hall, P., 2000. Creative cities and economic development. Urban Stud. 37: 639-649.

He, J., Gebhardt, H., 2013. Space of Creative Industries: A Case Study of Spatial Characteristics of Creative Clusters in Shanghai. Eur. Plan. Stud. 22: 2351-2368.

Howkins, J., 2010. The Creative Ecologies: Where thinking is a Proper Job. Routledge, London.

Hsee, C.K., Weber, E.U., 1999. Cross-national differences in risk preference and lay predictions. J. Behav. Decis. Making. 12, 165-179.

Jin, M., 2013. Shenzhen Urban renewal focus on cultural conservation. SZ News, Shenzhen.

Johnson, C. A., 1982. MITI and the Japanese Miracle. Stanford University Press, Stanford.

Keane, M., 2009a. Creative industries in China: four perspectives on social transformation, Int. J. of Cult. Policy, 15: 431-443.

Keane, M., 2009b. 'Great adaptations: China's creative clusters and the new social contract', Continuum, 23: 221-230.

Keane, M., 2011. China's New Creative Clusters: Governance, Human Capital and Regional Investment. Routledge, London and New York.

Kim, Y., Choi., M., 2015. Why have big construction companies replaced real estate developers in Korea? Int. J. of Urban Sci. 19: 206-223. 
Li, L., 2015. State or market: the role of the government in urban village regeneration in China. Int. J. of Urban Sci. 19: 157-167.

Li, S., Cheng, H., Wang, J., 2014. Making a cultural cluster in China: A study of Dafen Oil Painting Village, Shenzhen. Habitat Int. 41: 156-164.

Liu, X., Han, S., O'Connor, K., 2013. Art villages in metropolitan Beijing: A study of the location dynamics. Habitat Int. 40: 176-183.

Liu, X., Meng, Y., Wang, H. 2013. OCT-Loft Rennovation, Urbanus. URL: https://www.arquitectes.cat/iframes/paisatge/fotos_proj/8a_BIENNAL/P8031/P8031 F1.jpg (Accessed on Nov 25, 2016).

Markusen, A., 2013. Fuzzy concepts, proxy data: why indicators would not track creative placemaking success. Int. J. of Urban Sci. 17: 291-303.

NEWSGD., 2007. Shenzhen launches OCT-LOFT. URL: http://www.newsgd.com/culture/culturenews/200702080044.htm (Access on June 23, 2016).

O’Connor, J., Gu, X., 2012. Creative industry clusters in Shanghai: a success story? Int. J. Cult. Policy. 20, 1-20.

O'Connor, J., Liu, L., 2014. Shenzhen's OCT-LOFT: Creative space in the city of design. City, Cult. Soc. 5, 131-138.

O'Donnell, M., 2012. How should we judge the success of Shenzhen's cultural industry? Shenzhen Noted. Available:. http://shenzhennoted.com/2012/01/31/how-should-wejudge-the-success-of-shenzhens-cultural-industry/ (Accessed 21/06/2017)

O'Donnell, M. Wong, W, and Bach, J. 2017 Learning from Shenzhen: China's Post-Mao Experiment from Special Zone to Model City, Chicago, The university of Chicago Press.

OCT Group, 2014. OCT Group Website. Available:. http://www.chinaoct.com (Accessed $18 / 05 / 2014)$

OCT LOFT Company, 2014. The Creative Model of OCT Loft. Gold Wall Press, Beijing.

OCT Loft, 2015. Official Homepage. Available:. http://www.octLoft.cn/default (Accessed 28/08/2015)

OCT Magazine. 2010. 25 years to summit. OCT Mag. 39, 20-34.

Oi, J., 1992. Fiscal reform and the economic foundations of local state corporatism in China. World Polit. 45, 99-126.

Oi, J., 1995. The role of the local state in China's transitional economy. China Quart. 144, 1132-1149

Qianhai_Media, 2016. What Can We Say about the Shenzhen Cultural Industry? Available:. http://www.sanwen8.com/p/n9drctdo.html, (Accessed 28/11/2016)

Rantisi, N., 2004. The ascendance of New York fashion. Int. J. Urban. Regional. 28, 86106.

Ren, X., 2015. City power and urban fiscal crises: the USA, China, and India. Int. J. Urban Sci. 19, 73-81.

Ren, X., Sun, M., 2012. Artistic urbanization: Creative industries and creative control in Beijing. Int. J. Urban. Regional. 36, 504-521.

Rosenberg, N., 1983. Inside the Black Box: Technology and Economics. Cambridge University Press, Cambridge

Saich, T., 2010. Governance and Politics of China. Palgrave Macmillan, London. 
Saxenian, A., 1994. Regional Advantage: Culture and Competition in Silicon Valley and Route 128. Harvard University Press, Cambridge, MA.

Scott, A. J., 1996. The craft, fashion, and cultural products industries of Los Angeles: Competitive dynamics and policy dilemmas in a multi-sectoral image-producing complex. Ann. Assoc. Am. Geogr. 86, 306-23.

Scott, A. J., 1997. The cultural economy of cities. Int. J. Urban. Regional. 21, 323-339.

Shi, C., Zhu, S., Qing, W., 2012. Experience of cultural and creative industries park development in Shenzhen - Case study of The OCT-Loft, City of Design. J. Advert. Study (Academic Edition). 5, 65-75.

Shi, Y., Chen, Y., 2016. New city planning and construction in Shanghai: retrospective and prospective. Int. J. Urban Sci. 20, 49-72.

Shin, H., 2010. Urban conservation and revalorisation of dilapidated historic quarters: the case of Nanluoguxiang in Beijing. Cities. 27Sup, S43-S54.

Sonn, J., 2007. Insulation with solidarity as a political condition for an implementation of polarised development strategy: the South Korean experience and its theoretical implications. Int. Plan. Stud. 12, 221-240.

Sonn, J., 2017. MNE's R\&D and its local effects: Global R\&D network approach. Global Production Network Workshop, Hong Kong City University, Hong Kong.

Sonn, J., Gimm, D., 2013. South Korea's Saemaul (New Village) movement: an organisational technology for the production of developmentalist subjects. Can. J. Dev. Stud. 34, 22-36.

Sonn, J., Lee, D.. 2015. Heterogeneity as the source of the state's resilience: the case of spatial planning under state-led neoliberalization in South Korea. Int. J. of Urban Sci. 19: 364-378.

Sonn, J., Liu, X., 2014. The role of property development in the formation of a cultural cluster - some theoretical reflections. Kor. J. Regional Dev. 26, 157-174.

Sonn, J., Storper, M., 2008. The increasing importance of geographical proximity in knowledge production: An analysis of U.S. patent citations, 1975-1997. Env.Plan. A. 40, 1020-1039.

Statistical Bureau of Shenzhen, 2015. Shenzhen Statistical Yearbook, in: Statistical_Bureau_of_Shenzhen(Ed.), Shenzhen.

Sternberg, R.J., 1988. The nature of creativity: Contemporary psychological perspectives. Cambridge University Press, Cambridge.

Sun, M., 2010. The production of art districts and urban transformation in Beijing, $\mathrm{PhD}$ Dissertation in the Graduate College, University of Illinois at Chicago.

Wade, R., 1990. Governing the market: Economic theory and the role of government in East Asian industrialization. Princeton University Press, Princeton.

Walder, A.G., 1995. Local governments as industrial firms: an organizational analysis of China's transitional economy. Am. J. Sociol. 101, 263-301.

Wang, J., 2009. 'Art in capital': Shaping distinctiveness in a culture-led urban regeneration project in Red Town, Shanghai. Cities 26, 318-330.

Wang, J., Li, S., 2009. The rhetoric and reality of culture-led urban regeneration-a comparison of Beijing and Shanghai, China, Proceedings of the IFoU Conference Delft 2009, Amsterdam.

Webster, D., Muller, L., Cai, J., 2011. The emerging cultural economy in Chinese cities: early dynamics. Int. Dev. Plan. Rev. 33, 343-369. 
Wen, W., 2012. Scenes, quarters and clusters: New experiments in the formation and governance of creative places in China, Creative Industries. Queensland University of Technology, Brisbane St Lucia.

White, A., Xu, S., 2012. A critique of China's cultural policy and the development of its cultural and creative industries: the case of Shanghai. Cult. Trend. 21, 249-257.

Woo-Cumings, M., 1999. The developmental state. Cornell University Press, Ithaca and London.

Wu, F., 2003. The (post-) socialist entrepreneurial city as a state project: Shanghai's reglobalisation in question. Urban Stud. 40, 1673-1698.

Xie, J., 2012. Shenzhen abandoned old factory upgrade old and welcome the shift to high value-added industries carrier. SZ News, Shenzhen.

Yang, Z., Huang, W., 2010. Research on the current situation and solution of the creative industry development in Shenzhen. Hundred Sch. in Art 1, 5.

Zhang, T., 2014. OCT: From a theme park to a creative city. China Culture Daily, Beijing.

Zhang, J., Forthcoming. The Geographic political economy of art district formation in China: the case of Songzhuang, Geoforum

Zheng, J., 2011. 'Creative industry clusters' and the 'entrepreneurial city' of Shanghai. Urban Stud. 48, 3561-3582.

Zhong, S., 2010. Industrial restructuring and the formation of creative industry clusters: the case of Shanghai's inner city, Planning. University of British Columbia, Vancouver.

Zhou, J., Lei, Y., 2015. The spatial character of cultural and creative industrial park-the case of Shenzhen OCT Loft. Paper presented at 2015 Annual Meeting of Chinese Urban Planner.

Zukin, S., 1989. Loft living: culture and capital in urban change. Rutgers University Press, New Brunswick, New Jersey. 


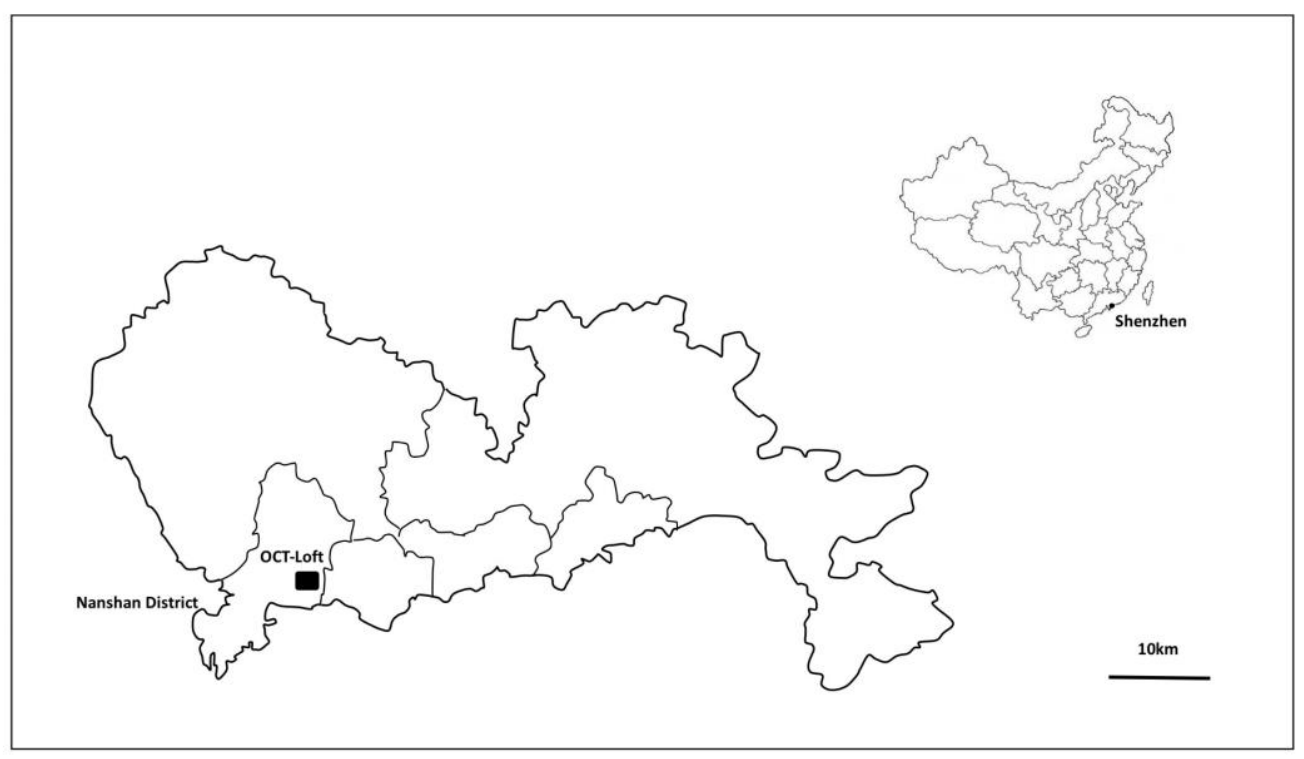

Figure 1 


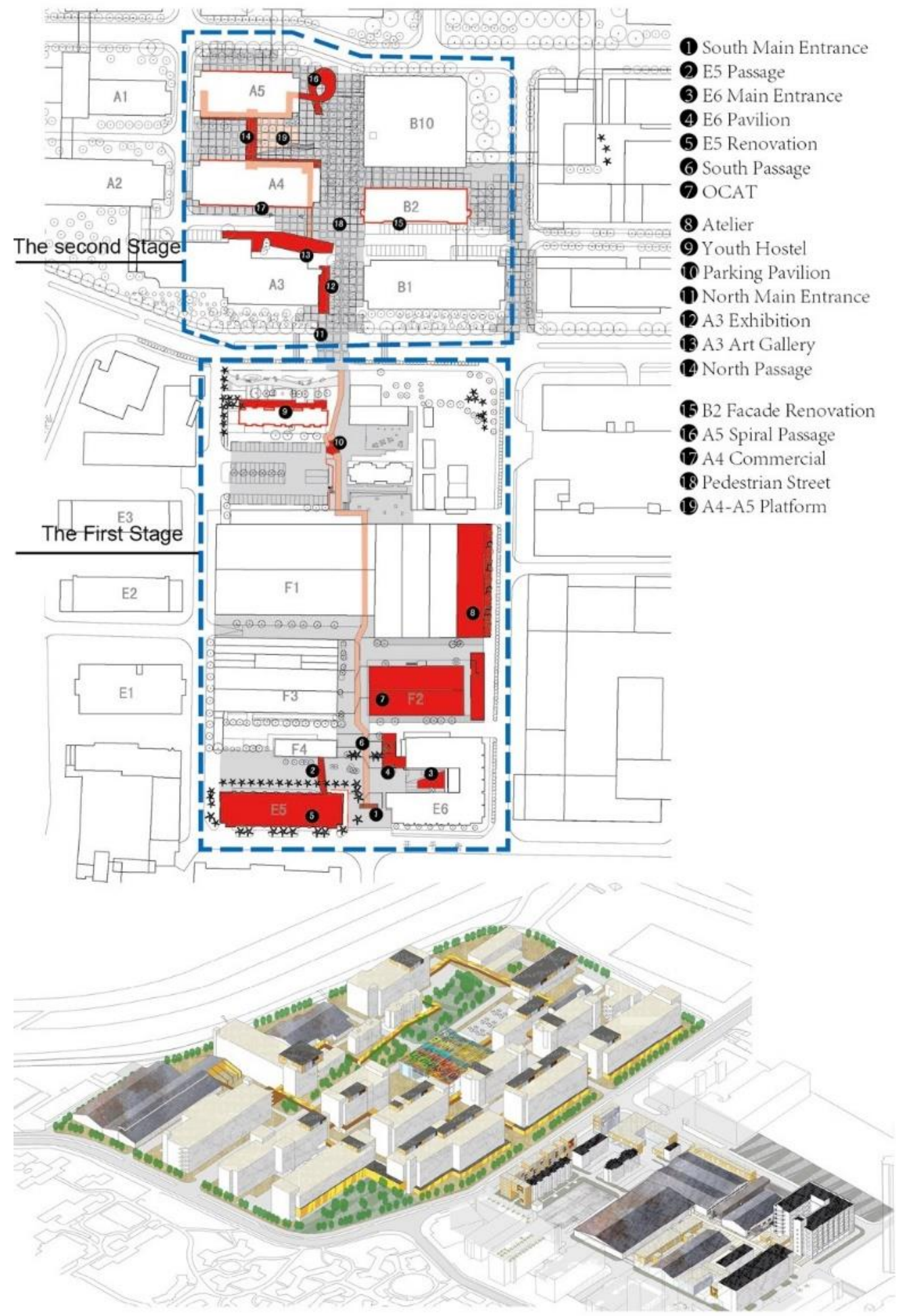

Figure 2 

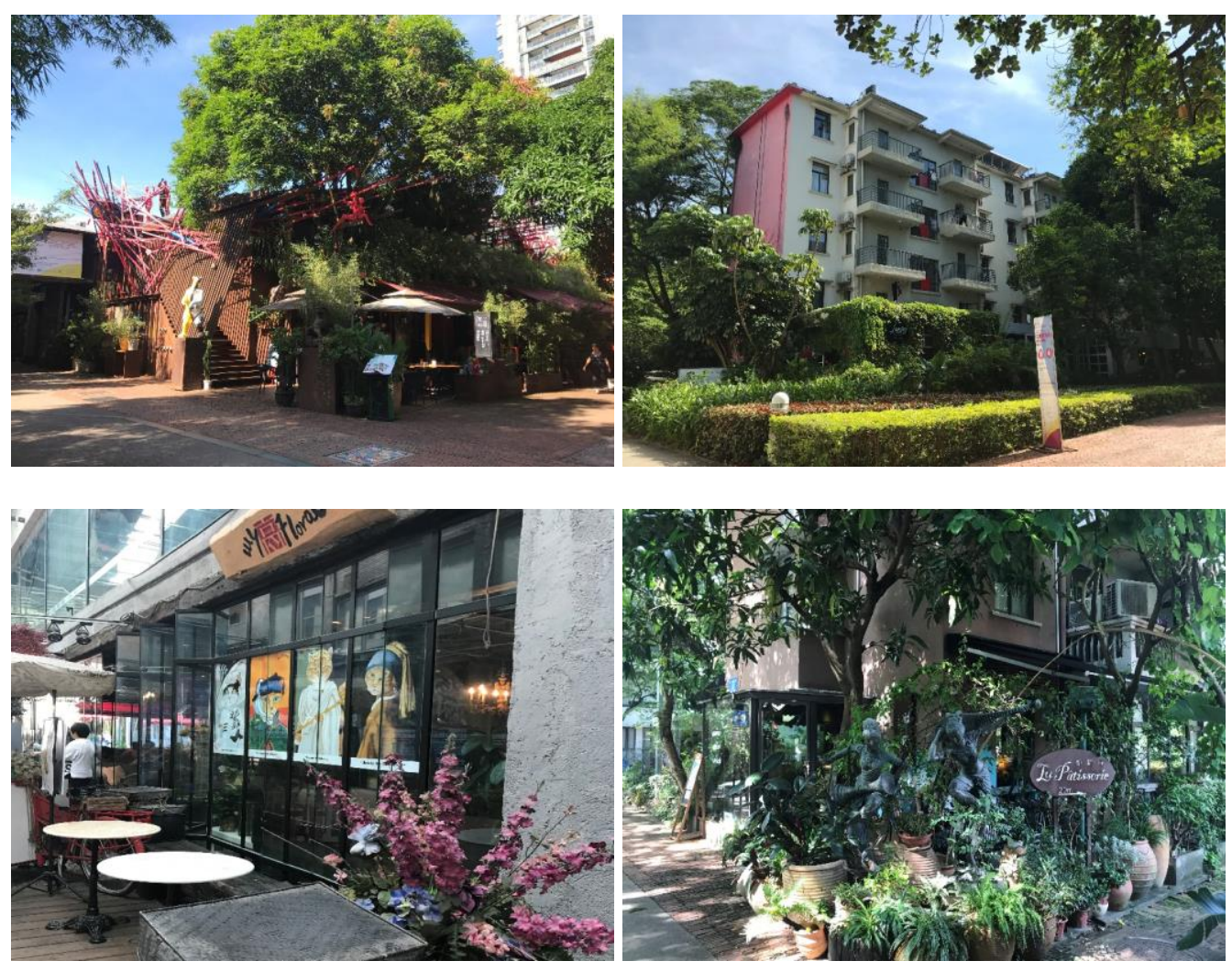
Figure 3

Source: Authors' own photos
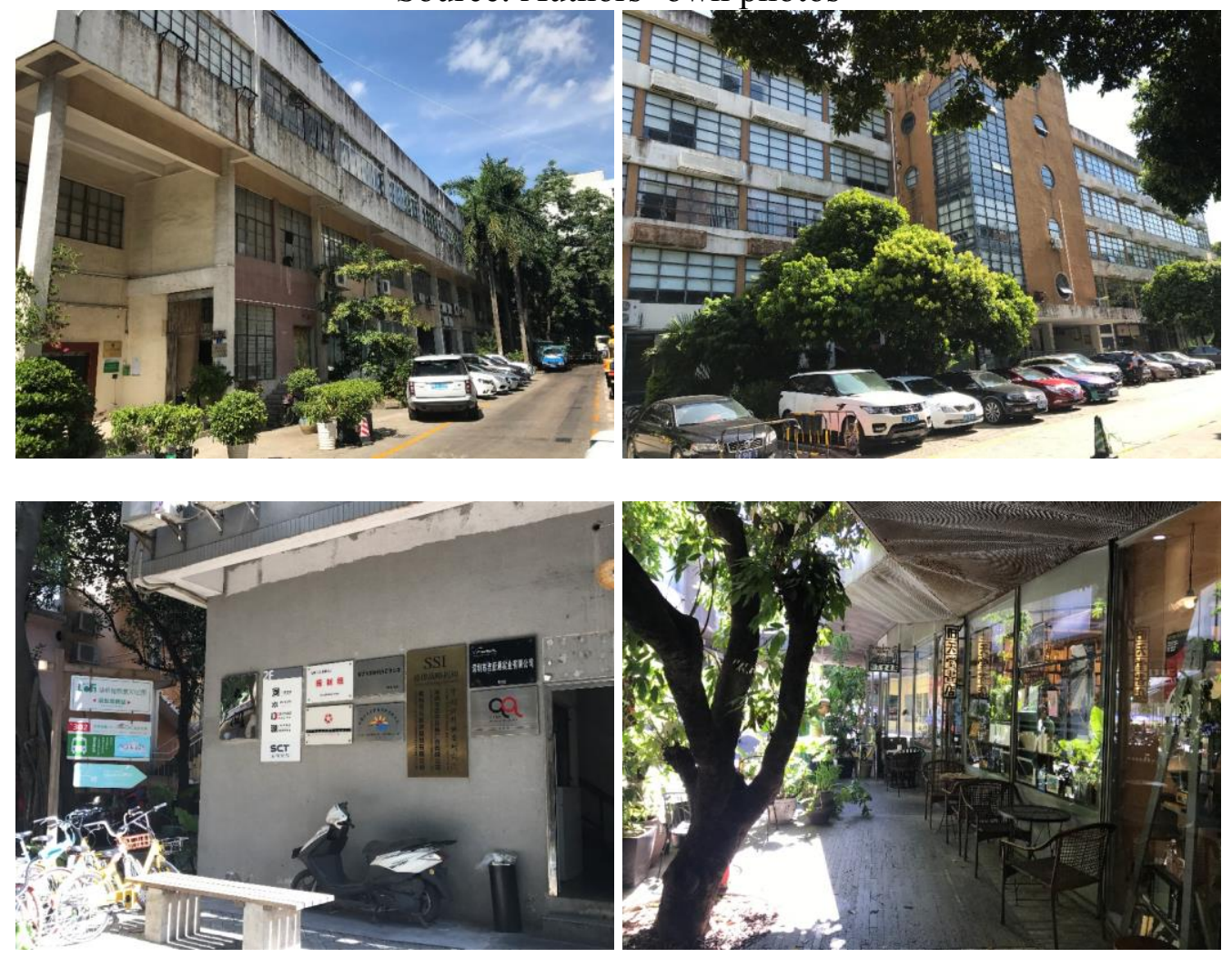

Figure 4

Source: Authors' own photos 